Lexis Vol. XLIV (2) 2020: 789-804

\title{
La circulación y lectura de los libros de caballería en el virreinato peruano: dos cuestiones por resolver
}

\author{
Pedro M. Guibovich Pérez \\ Pontificia Universidad Católica del Perú
}

\begin{abstract}
RESUMEN
Los libros de caballería fue uno de los géneros literarios más difundidos en el imperio español durante el siglo XVI e inicios del siglo XVII. A pesar de que se ha escrito que circularon y fueron leídos en el virreinato peruano, las evidencias documentales al respecto resultan insuficientes. En esta nota problematizo ambos aspectos a partir de la bibliografía existente y las fuentes documentales.
\end{abstract}

Palabras clave: libros de caballería, lectores, cultura letrada, virreinato peruano, conquistadores españoles

The Circulation and Reading of Chivalric Books in the Peruvian Viceroyalty: Two Questions to Be Resolved

\section{ABSTRACT}

Chivalry books were one of the most widespread literary genres in the Spanish Empire during the Sixteenth and early Seventeenth centuries. Although it has been written that they circulated and read in the Peruvian viceroyalty, the documentary evidence in this regard is insufficient. In this note, I problematize both aspects from the existing bibliography and documentary sources.

Keywords: Chivalric books, readers, literate culture, Peruvian viceroyalty, Spanish conquerors

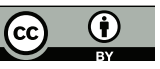

https://doi.org/10.18800/lexis.202002.011 
Toda mi vida (sacada la buena poesía) fui enemigo de ficciones como son libros de caballerías y otras semejantes. Las gracias de esto debo dar al ilustre caballero Pedro Mexía de Sevilla, porque con una reprehensión, que en Heroica obra de los Césares hace a los que se ocupan en leer y componer los tales libros, me quitó el amor que como muchacho les podía tener y me hizo aborrecerlos para siempre (Garcilaso de la Vega 2015, I: 493).

En estos elocuentes términos, el Inca Garcilaso de la Vega confesó su afición por los libros de caballería. Aunque es difícil determinar si los leyó antes de dejar el Cuzco en enero de 1560 o después, durante su estancia peninsular, es claro que, como un hombre culto de su tiempo, difícilmente pudo sustraerse al encanto de dicho género literario. Mas la lectura de la Historia imperial y cesárea, en la qual en summa se contienen las vidas y bechos de todos los césares emperadores de Roma, desde Julio César hasta el Emperador Maximiliano, del humanista español Pedro Mexía, lo habría llevado a cambiar de opinión.

A pesar de la opinión negativa de Pedro Mexía y de otros escritores, los libros de caballería gozaron de fortuna a lo largo y ancho del imperio español. La imprenta contribuyó notablemente a su difusión. Los impresores, siempre deseosos de obtener ganancias, no solo lanzaron una gran cantidad de ediciones, sino que además supieron adaptar la forma y el contenido de los relatos caballeros en función de los gustos del público lector (Lucía Megías 2000). Los libros de caballería fueron el género dominante de la prosa de ficción en la península ibérica y con una trascendencia en toda Europa occidental, ha escrito Daniel Gutiérrez Trápaga (2017: 692). La bibliografía sobre la producción, circulación y lectura del género en España es bastante extensa y sería largo y tedioso dar cuenta de ella.

No lo es tanto para el caso del virreinato peruano. Los trabajos de José Torre Revello (1940), Irving Leonard (1979) y Guillermo Lohmann (1944) mostraron que, a pesar de las prohibiciones legales, los libros de caballería fueron comercializados en los Andes. En el año 2008, con ocasión de la conmemoración del quinto centenario de la publicación del Amadís de Gaula, el tema de la recepción de la 
literatura caballeresca en la América colonial volvió a ser expuesto. Así, Javier Roberto González opinó que el conquistador y explorador se esforzó por trasladar al espacio americano las categorías y los elementos propios del espacio caballeresco ficcional, y se entregó de ese modo a una búsqueda incansable de sirenas, amazonas, gigantes, grifos, fuentes de la eterna juventud y ciudades encantadas, sencillamente porque necesitaba de ese marco para que su ideal heroico, moldeado en el caballero andante, pueda fructificar. En suma, sostiene, "los libros de caballería [...] vienen a influir de una doble manera en el conquistador: en la configuración de su ideal de vida, y en la determinación de una imagen apriorística del espacio americano (González 2008: 376). Y, en tiempos relativamente más recientes, encontramos que José Carlos Mainer escribió que la lectura de los libros de caballerías "activó también la febril imaginación de los conquistadores americanos" (Gutiérrez Trápaga 2017: 683). Se trata de una cuestión aún abierta a debate. Durante años he estado recopilando información sobre bibliotecas privadas e institucionales y otras evidencias sobre experiencias lectoras con miras a escribir un estudio comprehensivo sobre la circulación de los libros y su lectura en el virreinato peruano. Muchos géneros literarios aparecen bastante representados en la documentación, salvo uno: los libros de caballerías. Se trata de un género que circuló, pero que parece no haber tenido lectores. Llevado por la curiosidad, traigo dos cuestiones aún por resolver: de un lado, la circulación de los libros de caballería; y, de otro, la composición de su público lector en el virreinato.

\section{La “popularidad” de los libros de caballería}

Marcelino Menéndez Pelayo gustaba de insinuar que la fortuna de las novelas de caballerías en España no pasó nunca de ser una moda efímera, sostuvo Maxime Chevalier. Esta opinión, prosigue este último autor, no puede sostenerse, tratándose de un género literario cuya boga es manifiesta a finales del siglo XIV, llega a su cénit a mediados del siglo XVI y perdura hasta los años 1600. Las cifras 
elaboradas por Chevalier no dejan de impresionar: 267 ediciones entre 1501 y 1650, 157 de las cuales entre 1501 y 1550, 86 entre 1551 y 1600, 24 entre 1601 y 1650; 46 novelas originales impresas entre 1510 y 1602, 36 de las cuales entre 1510 y 1551. El hispanista francés sostiene, siguiendo a Martín de Riquer, que se sitúan más bien por debajo que por encima de una realidad editorial conocida de manera incompleta. Las cifras representan que se trató de la más amplia producción literaria del Siglo de Oro en cuanto a novela, y únicamente comparables con la cantidad de ediciones que había de alcanzar la llamada novela cortesana en el siglo XVII (Chevalier 1976: 66-67).

Como es conocido, los libros de caballería y otros relatos cortos caballerescos gozaron de popularidad entre autoridades políticas, miembros de la jerarquía eclesiástica y otros grupos de la sociedad peninsular. Tal situación, era de esperar, que generase reparos entre aquellos que estimaban que la lectura de tales ficciones era contraproducente a la moral y buenas costumbres. Entre los críticos se hallaron Luis Vives, Alejo Venegas, Melchor Cano, fray Luis de Granada, Benito Arias Montano, fray Antonio de Guevara, Francisco Cervantes de Salazar y otros. Es probable que el reclamo de estos y otros miembros de la sociedad española hallara eco en las Cortes reunidas en Valladolid. Así, estas, en 1555, solicitaron al rey confiscar y quemar los "libros de caballerías y otros del estilo", así como prohibir su impresión. Fundamentaban su pedido en el "muy notorio daño que en estos reynos ha hecho y haze a hombres moços y donzellas y a otros géneros de gentes leer libros de mentiras y vanidades como son Amadís y todos los libros que después dél se han fingido de su calidad y letura, y coplas y farsas de amores y otras vanidades" (Reyes Gómez 2000, II: 795-796). Los asambleístas consideraban que los "mancebos donzellos por su ociosidad principalmente se ocupan en aquello, desvanecense y aficionase en cierta manera a los casos que leen en aquellos libros haver acontecido, ansí de amores como de armas y otras vanidades, y aficionados quando se ofrece algún caso semejante danse a él más a rienda suelta que si no lo oviesse leydo". Igual de perniciosa era la lectura entre las 
mujeres, ya que decían que había sucedido que habiendo dejado la madre a la hija encerrada en casa, y creyéndola recogida, esta última se queda leyendo tales obras. Pero, acaso, el mayor perjuicio que causaba la lectura era que cuanto más se aficionaban a ella, más se apartaban de la doctrina cristiana (2000, II: 796).

La preocupación acerca del efecto pernicioso sobre la conducta de los lectores se hizo extensiva a América. De 1531 es una real cédula, promulgada por la reina, dirigida a los oficiales de la Casa de Contratación, en Sevilla, que les ordenaba no consentir el envío a América de "libros ningunos de historias y cosas profanas, salvo tocante a la religión cristiana e de virtud". De lo que se trataba era de impedir que los indios y otros pobladores de las Indias "se ejerciten y ocupen” en ellos (2000, II: 783). Una cuestión que demandaba atención, a medida que avanzaba el proceso de colonización, era la aculturación de los indígenas. Se imponía la necesidad de establecer límites y restricciones en cuanto a su acceso a la cultura impresa procedente del Viejo Continente. La alfabetización de los indígenas podía paradójicamente poner en riesgo su evangelización y conducta moral. La real cédula dirigida a los oidores de la Audiencia de Lima, fechada en 1543, los instruye para que no consientan ni den lugar a que se vendan ni circulen "libros de romanze de materias profanas, y fábulas, así como son libros de Amadís y otros desta calidad, de mentirosas historias". Las consideraciones para esta disposición expresan el temor de que los indios ladinos se aficionen a ellos y dejen de leer "los libros de sancta y buena doctrina", con lo cual aprenderán malas costumbres y vicios; y, por añadidura, desacreditarán la autoridad de las Sagradas Escrituras "y otros libros de Doctores, creyendo como gente no arraygada en la fe, que todos nuestros libros eran de una autoridad y manera" (2000, II: 787).

Las autoridades eclesiásticas se hicieron eco de las restricciones impuestas por la corona acerca de lo que se consideraban lecturas no permitidas y, por ende, perniciosas. El Segundo Concilio Provincial, celebrado en Lima en 1567, encargó a los obispos examinar los libros en latín y romance antes de su venta a fin de evitar la circulación de ideas contrarias a la fe; como también no consentir 
el uso de "libros deshonestos o lascivos ni profanos y de amores y cavallerías” en las escuelas de los muchachos (Bartra 1982: 152). Las disposiciones se insertaron en el apartado De lo que toca a espanoles, por lo que se infiere que no competían a los indígenas.

\section{La circulación}

Como muchas otras mercaderías, y a pesar de los comentarios de los moralistas y la legislación, libros de muy diversa temática, entre ellos los de caballerías, cruzaron el Atlántico con destino a América desde una etapa temprana de la colonización. Los libreros de los principales centros editoriales del Viejo Continente descubrieron el enorme potencial de ganancias que podía tener el mercado americano. Como no podía ser de otra manera, los impresores de Sevilla, al igual que los de otras ciudades españolas, se involucraron en el comercio americano. De acuerdo con Leonard, en el siglo XVII, impresores sevillanos sin escrúpulos hicieron verdaderas fortunas exportando a las colonias grandes cantidades de libros no autorizados, en particular piezas de teatro en tres actos — que gozaban del especial favor del público-y ediciones de trabajos mediocres falsamente atribuidos a conocidos escritores. Sin embargo, durante la primera mitad del siglo XVI, la influencia de los impresores en la capital del Guadalquivir condujo al arte tipográfico a un grado de perfección sin precedentes. Al parecer, la más afamada de las firmas editoriales era la casa Cromberger, que durante años disfrutó de derechos exclusivos para abastecer de libros a la región conquistada por Cortés (Leonard 1979: 104).

La cabeza de la familia, Jacobo Cromberger, de origen alemán, era un experto en tipografía y un astuto comerciante que llegó a Sevilla en 1500; estableció una imprenta allí, y después otras en Lisboa y Évora. Su establecimiento coincidió, observa Leonard, con el auge de la moda de los libros de ficción, lo cual brindó a las editoriales un importante impulso comercial. En este contexto, sumado al monopolio mercantil con América concedido a Sevilla por la corona, hizo de esta ciudad el centro de publicaciones más importante de la 
península durante la mayor parte del siglo XVI. Se han identificado 751 títulos de diferentes obras publicadas allí durante ese periodo; pero con seguridad la cifra fue mayor. Los libros de caballería constituyeron un porcentaje significativo de esa producción, aunque los datos al respecto son por el momento aproximados. La primera edición de Oliveros de Castilla fue publicada por la imprenta de Cromberger en 1507, así como otras obras del mismo género. Algunas de estas ediciones seguramente fueron enviadas al mercado americano, según Leonard (1979: 105). En tiempos más recientes, Clive Griffin ha matizado lo sostenido por el investigador norteamericano. Griffin sostiene que no hay constancia que la familia Cromberger ganara mucho dinero con el monopolio libresco, ni que existiera una demanda relevante de libros impresos en la Nueva España en los años anteriores a la fundación de la Universidad en la ciudad de México. Resulta curioso, sostiene el mismo autor, que no se hayan encontrado en los archivos sevillanos, documentos que registren el envío de remesas de libros por parte de la familia Cromberger entre 1537 y 1546. Pero observa que el ritmo de producción del taller sevillano de los Cromberger parece registrar una notable actividad cada año poco antes de la salida de las flotas atlánticas, lo que quizá indique que, en efecto, imprimieron ediciones destinadas a las Indias. "La evidencia parece, por el momento, contradictoria", concluye Griffin (2010: 8-9).

Las primeras noticias acerca de la existencia del comercio de libros en el virreinato se remontan a mediados del siglo XVI. A Leonard debemos el conocimiento de la referencia más antigua de un embarque de libros con destino al Perú. Se trata de la remisión de 79 ejemplares que hizo Alonso Cabezas, vecino de Los Reyes, probablemente desde Sevilla el 1 de noviembre de 1549, a su compañero "Pero Hortiz" que residía en Nombre de Dios, a bordo de la nave La Magdalena. La mayor parte de las obras remitidas eran de carácter religioso y junto a estas había una Crónica del rey don Rodrigo y nueve "novelas de caballería", sin especificar los títulos (Leonard 1979: 111). 
Los mercaderes de libros o libreros eran los principales abastecedores de novelas de caballería y relatos cortos caballerescos ${ }^{1}$. Así, por ejemplo, el 22 de febrero de 1583, Francisco de la Hoz y el librero Juan Jiménez del Río suscribieron en Lima un contrato por el cual el primero se comprometió a adquirir en España diversos libros para el segundo (1979: 343-344). Entre ellos, diversos libros de caballería, tales como el Libro del valeroso e invencible Príncipe don Belianís de Grecia, de Jerónimo Fernández; el Espejo de principes... se cuentan los inmortales hechos del caballero de Febo, de Diego Ortúñez de Calahorra; la Crónica de Lepolemo, llamado Caballero de la Cruz, de Alonso de Salazar; la Historia... del caballero D. Olivante de Laura, príncipe de Macedonia, de Antonio de Torquemada; Los quatro libros del muy esforzado y muy virtuoso Caballero Amadís de Gaula, atribuido a Vasco de Lobeyra; y la Historia del príncipe Felixmarte de Hircania, de Melchor de Ortega. Más allá del interés que revisten los títulos solicitados, resultan muy ilustrativas las especificaciones de Jiménez del Río a de la Hoz acerca de las ediciones que debía adquirir en la Península. Así, por ejemplo, lo instruye a que tan solo compre la primera y segunda partes del Belianís de Grecia y no las tercera y cuarta partes "porque acá hay muchas encoadernados en pergamino”. En tanto que los ejemplares de El caballero de Febo debían ser de los que "tengan los principios de colores”. Sin duda, el librero era un hombre al tanto de las novedades bibliográficas aparecidas en la península ya que especifica que las ediciones del Amadís que requiere son aquellas compuestas de "seis cuerpos y cada quatro de Amadís es un cuerpo encuadernados en pergamino”. Consciente de la demanda del público local por las aventuras de Felixmarte de Hircania, le reclama no solo el relato de Melchor de Ortega, sino "lo que más hubiere salido dél asta oy” (1979: 343-344)².

Acerca de las características de estos últimos, consultar Infantes (1991).

2 A pesar del tiempo transcurrido, sigue siendo útil el estudio de Eisenberg (1979) sobre las ediciones y estudios de los libros de caballería. 
Junto a estos textos, de la Hoz debía hacerse de "20 resmas de menudencias", entre las que se incluían coplas, confesionarios, hagiografías y relatos breves caballerescos. Entre estos últimos se incluían la Historia del emperador Carlomagno y de los doce pares de Francia, la Historia del rey Cañamor y del infante Turián, su bijo; la Crónica de los muy notables cavalleros Tablante de Ricamonte y de Jofre. En cuanto a "menudencias", se encargan las "nuebas que hubiera". Las impresiones habían de ser de Alcalá o de otro lugar, pero todas bien encuadernadas (1979: 347).

En las escrituras notariales suscritas entre comerciantes es relativamente común encontrar libros de caballería. Aquí algunos ejemplos. El 23 de agosto de 1600, Lorenzo Vázquez, vecino de Lima, como principal deudor, y Antonio Hernández de Acosta, librero, ambos residentes en Lima, extendieron carta de obligación de pago en favor de Diego de Soria, vecino de Sevilla, y de Alonso Rodríguez de León, morador en Lima, por 1498 pesos, valor de diversos libros. Entre ellos se incluían doce ejemplares del Amadís de Grecia y cuatro del Belianís de Grecia ${ }^{3}$. Uno de los libreros más activos entre fines del siglo XVI e inicios del XVII fue Andrés de Hornillos. El 5 de marzo de 1597, él y Pedro de Salvatierra, como su fiador, otorgaron carta de obligación de pago en favor de los herederos de Pedro López de Zúñiga, alcalde de corte de Lima, del inquisidor Pedro Ordóñez y Flórez, en representación de dichos herederos, y de Jerónimo de Adrada, por la cantidad de 2000 pesos de plata, correspondientes al valor de un lote de libros que perteneció a Francisco Butrón. Entre los libros se incluían siete ejemplares de El Caballero de Febo, cinco de El Palmerín de Oliva, cuatro del Caballero de la Cruz, dos del Libarte de Grecia, quince de El Príncipe Celidón de Iberia, once de El caballero determinado, uno de la Historia del Cid, catorce de El Caballero de la Estrella y veintiocho del Oliveros de Castilla ${ }^{4}$. A medida que avanza el siglo

\footnotetext{
3 Archivo General de la Nación. Protocolo del escribano Diego López de Salazar, No. 992, año 1600 , ff. $1769 \mathrm{v}-1777 \mathrm{r}$.

4 Archivo General de la Nación, Protocolo del escribano Cristóbal de Aguilar Mendieta, No. 5, años 1597-1598, ff. 260r-280r.
} 
XVII, los libros de caballería van progresivamente desapareciendo entre las existencias de mercaderes de libros. En 1623 falleció de Hornillos, y, como era usual, después de su muerte se procedió a hacer el inventario de sus pertenencias con miras a pagar sus deudas y mandas testamentarias. En el registro de su tienda de libros, practicado el 29 de agosto de aquel año, no se halló ningún libro de caballería ${ }^{5}$.

Las escrituras mercantiles registran que algunos libros de caballería alcanzarán el Cuzco a inicios del siglo XVII. Más aún, su lectura nutrió el imaginario festivo de los pobladores de los Andes. Hace ya muchos años que Francisco Rodríguez Marín documentó la celebración de un juego de sortijas en Pausa, en la sierra sur del Perú, en la que los participantes de la misma aparecieron caracterizados como personajes de los libros de caballería (Rodríguez Marín 1911).

\section{La lectura}

Aunque la circulación de los libros de caballería está principalmente documentada en el ámbito limeño, no es el caso de su lectura. Se trata de una cuestión controvertida. Ida Rodríguez Prampolini (1948) fue la primera en sostener que la conquista española de América había estado guiada por ideales caballerescos, en parte nutridos por la lectura de las novelas de aventuras. Un paso mayor lo dio Leonard, quien documentó la difusión de los títulos y sostuvo que su lectura "constituyó un acicate para lanzarlos a fantásticas aventuras a través del mundo, súbitamente ensanchado, en que vivían” (Leonard 1979: 33). El propio Leonard nunca fue conclusivo, consciente de las limitaciones de su tesis llegó a escribir "La influencia de esta literatura sobre el pensamiento y acción de los lectores es incuestionable, aunque no se la pueda medir con exactitud. El conquistador, como elemento aventurero y dinámico de la sociedad española, mal podía escapar a la incitación de semejantes fantasías, aunque tampoco este

5 Archivo General de la Nación, Protocolo del escribano Diego Sánchez Vadillo, No. 1755, año 1623, ff. 3982r-3985v. 
efecto se pueda demostrar con pruebas documentales" (1979: 41) . A pesar de estas y otras prevenciones, la tesis de Leonard ha tenido una fortuna sin par debido a la lectura poco atenta de su obra. En cualquier caso, la única aproximación crítica que conozco a la tesis de Leonard ha sido la de Rolena Adorno (1992). Esta autora señala que el grado en que las ficciones y valores caballerescos influyeron en la psicología de los conquistadores permanece abierto al debate. Tales obras ciertamente proporcionaron un lenguaje de referencias culturales para describir las experiencias de los soldados. Así, al analizar la obra de Bernal Díaz del Castillo, Adorno argumenta que las novelas de caballería ni inspiraron las acciones de los soldados que participaron en la conquista de México, ni su acto de narrar. En su lugar, ellas fueron la solución a su búsqueda por una forma para comunicar la magnificencia y el esplendor de su primera impresión de Tenochtitlán. Los libros de caballería fueron un punto común de referencia por el que el lector de la España del siglo XVI podía dar significado al relato de un lugar no visto (Adorno 1992: xxxi-xxxii). A pesar de las observaciones de Adorno a propósito de la tesis de Leonard, persiste la creencia de que las novelas de caballería fueron leídas por los conquistadores e influyeron en su comportamiento como ya se ha visto

No ha faltado autor que haya ido más allá al sostener que el género caballeresco circuló entre la población nativa. De acuerdo con Carlos Alberto González, dicho género tuvo gran impacto entre los indígenas, necesitados de evadir y trascender el, a sus ojos, ajeno y extraño imaginario occidental que se les estaba imponiendo. Sostiene el mismo autor que, en consonancia a su visión del mundo, los indígenas gustaron de los hechizos, los encantamientos y las artimañas maravillosas de hadas, magos y brujos, y el valor guerrero de los caballeros literarios (González Sánchez 2007: 247). La tesis es sugerente pero carente de fundamento documental. El único testimonio acerca de la supuesta afición de los indios por los libros de caballería procede del cura doctrinero Bartolomé Álvarez, quien

6 Las cursivas son mías. 
en un memorial dirigido a Felipe II, compuesto en 1588, sugería la intervención de la Inquisición en la persecución y castigo de los indios idólatras. En su opinión, después de varias décadas de evangelización, la idolatría nativa persistía, y veía con preocupación el interés de los nativos por los libros de derecho, ya que su lectura los podía convertir en potenciales litigantes. Más aún, los indios interpretaban al pie de la letra las historias caballerescas que, por añadidura, los hacían muy crédulos: “de preguntarles si vieron en aquella sazón a Reinaldos de Montalván que estaba en aquel acto, y dizen que si y dan las señas, y si vieron al Cid Ruy Díaz, y dicen que sí y lo que estaba haciendo" (Álvarez 1998: 72). El testimonio del clérigo hay que ponerlo en cuestión, porque no he podido confirmar sus afirmaciones en otras fuentes contemporáneas.

En este punto, convendrá preguntarse por cuál fue el público lector de los libros de caballerías. Ninguno de los conquistadores que participaron en la empresa de dominar el Tahuantinsuyo ha dejado testimonio de su lectura de libros de caballerías, como tampoco ninguno de los cronistas que la historiaron. Habrá, pues, que volver la mirada hacia los inventarios de bibliotecas privadas en busca de evidencias. Para el caso peruano, solo he podido documentar la presencia del género en dos colecciones limeñas del primer tercio del siglo XVII: el capitán Martín de las Salas poseía “cinco libros de cuerpo grande de istorias de Amadis, los unos de dos cuerpos y los tres de a quatro cuerpos"; y el comerciante portugués de origen judeoconverso, Manuel Bautista Peres, una copia de "el caballero de Febo” (Guibovich Pérez 2016: 163), pero, una vez más, conviene recordar que posesión no significa necesariamente lectura.

Un género afín y hermano de los libros de caballerías fue el de los relatos breves caballerescos. Los libreros limeños importaron gran cantidad de estos textos, más baratos que los libros de caballerías. El único testimonio que tenemos de su lectura es tardío. A inicios de la década de 1770, Alonso Carrió de la Vandera, en su

7 AGN. Protocolo del escribano Gerónimo Bernardo de Quirós, No. 219, años 16191621, f.333. 
condición de comisionado para el mejoramiento del sistema de correos entre Montevideo y Lima, llegó a Tucumán, donde visitó la casa de un "caballero", en quien reparó "que se explicaba en un modo raro y que hacía preguntas extrañas”. Pero acaso lo que más le llamó la atención a Carrió de la Vandera fue que, sobre una mesa, el referido personaje tenía "cuatro libros muy usados y casi desencuadernados”. Estos eran la Historia Oriental de las Peregrinaciones de Fernán Méndez Pinto; el Teatro de los dioses de la gentilidad, de Baltasar de Vitoria; la Historia de los bandos de Zegríes y Abencerrajes o Guerras civiles de Granada, de Ginés Pérez de Hita; y la Historia de Carlomagno y de los doces Pares de Francia ${ }^{8}$. El comisionado, luego de hojear los libros, que conocía porque los había leído en su juventud, alabó la "librería” y le preguntó al caballero si había leído otros textos, a lo que este le respondió que “aquellos los sabía de memoria y porque no se les olvidasen los sucesos, los repasaba todos los días, porque no se debía leer más que en pocos libros y buenos". La respuesta del caballero le pareció extravagante (Concolocorvo 1973: 118). No debe extrañar que así fuera porque Carrió de la Vandera estaba muy familiarizado con la literatura de su tiempo y, como tal, mostró extrañeza ante una colección de libros tan pequeña que sarcásticamente calificó de "librería” y una inusual práctica de la lectura. Al igual que al comisionado de correos, a nosotros no deja de llamarnos la atención la presencia de la Historia de Carlomagno. Esto porque no he podido documentar en otras colecciones de libros contemporáneas dicho título. Sin embargo, su lectoría en Tucumán muestra la pervivencia del interés por las historias de caballerías avanzado el siglo XVIII.

\footnotetext{
8 Se trata de la Historia del emperador Carlomagno y de los doce pares de Francia. La primera edición fue publicada por Cromberger en Sevilla, en 1521; se conocen reimpresiones hechas en el mismo lugar, en los años 1534, 1535 y 1549 (Lucía Megías 2000: 53). Fue impresa varias veces en los siglos XVII y XVIII. En un embarque de libros a América, en 1586, aparecen 12 ejemplares (Torre Revello 1940: 218). Sobre el problema de la autoría y características de la Historia del emperador Carlomagno, véase Luna Mariscal (2010).
} 


\section{A modo de conclusión}

La circulación de los libros de caballerías está documentada en el virreinato peruano, en particular en Lima; pero más allá del ámbito urbano, las referencias son escasas. A la fecha no he encontrado testimonios de la lectura de dicho género. Pero soy optimista, ya que el campo de la historia del libro y la lectura en el Perú colonial, a diferencia de la Nueva España, es un campo poco explorado. Estimo que aún queda mucho trabajo por hacer en los archivos históricos y en el corpus de la literatura colonial impresa y manuscrita. Acaso una mayor investigación permitirá resolver estas y otras cuestiones sobre las aficiones literarias de los miembros de la sociedad colonial.

\section{Referencias bibliográficas}

AdORno, Rolena

1992 "Introduction". En Books of the Brave: Being an Account of Books and of Men in the Spanish Conquest and Settlement of the Sixteenth-Century New World, de Irving A. Leonard. Berkeley: California University Press, ix-xlvii.

Álvarez, Bartolomé

1998 De las costumbres y conversión de los indios del Perú. Memorial a Felipe II (1588). Madrid: Polifemo.

BARTRA, Enrique (ed.)

1982 Tercer Concilio Limense 1582-1583. Lima: Facultad Pontificia y Civil de Teología de Lima.

Chevalier, Maxime

1976 Lectura y lectores en la España de los siglos XVI y XVII. Madrid: Ediciones Turner.

CONCOLOCORVO

1973 El lazarillo de ciegos caminantes. Edición de Emilio Carilla. Barcelona: Editorial Labor.

Eisenberg, Daniel

1979 Castillian Romances of Chivalry in the Sixteenth Century. Londres: Grant \& Cutler. 
García, Idalia y Pedro Rueda (comps.)

2010 Leer en tiempos de la colonia: Imprenta, bibliotecas y lectores en la Nueva España. Ciudad de México: Universidad Nacional Autónoma de México.

Garcilaso de la Vega

2015 Obras completas. Edición y notas de Carlos Araníbar. Lima: Ministerio de Relaciones Exteriores, 2t.

GonzÁLez, Javier Roberto

2008 "Libros de caballerías en América". En Amadís de Gaula. 1508. Quinientos años de libros de caballería. Eds., Biblioteca Nacional de España y Sociedad Estatal de Conmemoraciones Culturales Madrid. Madrid: A.G. Palermo, 369-382.

GonzÁlez Sánchez, Carlos Alberto

2007 Homo viator, homo scribens. Cultura gráfica, información y gobierno en la expansión atlántica (siglos XV-XVII). Madrid: Marcial Pons.

GrIFFIN, Clive

2010 "La primera imprenta en México y sus oficiales". En Leer en tiempos de la Colonia: imprenta, bibliotecas y lectores en la Nueva España. Comp., García y Rueda, 3-19.

Guibovich Pérez, Pedro

2016 "La cultura libresca de un converso". En Auto de la fe, celebrado en Lima a 23 de enero de 1639, de Fernando de Montesinos. Edición crítica de Marta Ortiz Canseco. Coordinación de Esperanza López Parada. Madrid/Frankfurt: Iberoamericana/ Vervuert. <https://doi.org/10.31819/9783954875979-005>

Gutiérrez Trápaga, Diego

2017 "La prosa de ficción en algunas historias de la literatura reciente: valoración cuantitativa de fuentes, metodología y principios de investigación”. eHumanista. 37, 680-695.

INFANTES, Víctor

1991 "La narración caballeresca breve". En Evolución narrativa e ideológica de la literatura caballeresca. Ed., María Eugenia Lacarra. Bilbao: Universidad del País Vasco, 165-181.

LEONARD, Irving

1979 Los libros del conquistador. México: Fondo de Cultura Económica. 
LEONARD, Irving

1992 Books of the Brave Being an Account of Books and Men in the Spanish Conquest and Settlement of the Sixteenth-Century New World. Berkeley: California University Press.

Lohmann Villena, Guillermo

1944 “Los libros españoles en Indias”. Arbor. II. 6, 221-249.

Lucía Megías, José Manuel

2000 Imprenta y libros de caballerías. Madrid: Ollero y Ramos.

Luna MariscaL, Karla Xiomara

2010 "Aspectos ideológicos de la traducción y recepción de las historias caballerescas breves". Cabiers d'études hispaniques médiévales. 33, 127-153.

Reyes Gómez, Fermín de los

2000 El libro en España y América. Legislación y censura (siglos XVXVIII). Madrid: Arco Libros, 2t.

Rodríguez Marín, Francisco

1911 El Quijote y Don Quijote en América. Madrid: Librería de los Sucesores de Hernando.

Rodríguez Prampolini, Ida

1948 Amadises de América. La hazaña de Indias como empresa caballeresca. México: Junta Mexicana de Investigaciones Históricas.

TORre Revello, José

1940 El libro, la imprenta y el periodismo en América durante la dominación española. Buenos Aires: Jacobo Peuser.

Recepción: 20/01/2020

Aceptación: 20/04/2020 